\title{
Motivational influences on word recognition: I. Foveal and parafoveal viewing
}

\author{
EVA DREIKURS FERGUSON \\ Southern Illinois University at Edwardsville, Edwardsville, Illinois
}

\begin{abstract}
The effects of motivation (hunger vs. satiation) on tachistoscopic word recognition were investigated. Overall procedures were identical for foveal viewing (Experiment 1) and parafoveal viewing (Experiment 2). Results with foveal viewing confirmed earlier findings (Ferguson, 1983) that hunger facilitated word recognition and no need-relevance effects were evident. Under foveal viewing, words were recognized significantly earlier under conditions of hunger, but overt responding was not significantly faster. Under parafoveal viewing, no significant motivation effects occurred. It is possible that different processing mechanisms operate under parafoveal and foveal viewing conditions.
\end{abstract}

The present experiments continue work by Erwin and Ferguson (1979) and Ferguson (1983) to assess how motivation affects word recognition. Motivation is characterized by arousal (Malmo, 1957) and direction (cues, goaldirection). Arousal refers to the overall excitability of the individual: increased alertness, energy availability and use, and responsiveness. This meaning of arousal differs from the one that focuses on activation of specific parts of the brain by techniques such as verbal memory load (Hellige \& Cox, 1976). Motivation and arousal are more fully discussed by Ferguson (1982) and Humphreys and Revelle (1984).

Early research on the arousing effects of motivation used hunger and thirst (Taylor, 1956) and direct brain stimulation (Fuster, 1958). In contast, researchers of directive or need-relevance effects studied mood congruence for memory (Bower \& Cohen, 1982) or, in early studies, congruence between an internal state and perception (McClelland \& Liberman, 1949; Sanford, 1937).

Early tachistoscopic threshold studies found little support for either arousal or need-relevance effects. Food and water deprivation did not significantly lower recognition thresholds (Taylor, 1956; Wispé \& Drambarean, 1953); need-relevant stimuli were not unequivocally recognized sooner than stimuli that were not need relevant. When data appeared to support the need-relevance hypothesis (Wispé \& Drambarean, 1953), they were probably due to artifacts resulting from inadequate control of word categories. Only a study using direct brain stimulation (Fuster, 1958) found evidence that arousal (as energizing) facilitated tachistoscopic stimulus recognition. The traditional early studies presented stimuli repeatedly, with duration or brightness increased upon each presentation, so that repetition was confounded with altered conditions

Grateful acknowledgment is given to the Research and Projects Office, Southern Illinois University at Edwardsville, for continued support of this research. Requests for reprints should be sent to Eva Dreikurs Ferguson, Psychology Department, Southern Illinois University at Edwardsville, Box 1121, Edwardsville, IL 62026. (duration or brightness). Recent research showed that repetition itself leads to pecreptual learning and to memory of the presented material (Graf \& Mandler, 1984; Jacoby, 1983), and that information processing occurs at levels below awareness (Fowler, Wolford, Slade, \& Tassinary, 1981; Kunst-Wilson \& Zajonc, 1980; Marcel, 1983). Early tachistoscopic studies that utilized the traditional threshold procedure failed to find motivation effects on stimulus recognition, possibly because of insufficiently sensitive procedures.

A dormant period followed the early tachistoscopic studies. Then Erwin and Ferguson (1979) developed a procedure that did not confound repetition with increased stimulus duration or brightness. They presented a word repeatedly for $10 \mathrm{msec}$ until correct recognition, and they found that thirst and hunger significantly facilitated word recognition. The arousing (energizing), but not the directive, dimension of motivation was significant. No differential need-relevance effect was evident. Using different words, fonts, and color of lettering, Ferguson (1983) verified the facilitating arousing effect of hunger on word recognition, and again found no support for need relevance in word recognition. A possible explanation for Ferguson's findings of hunger- and thirst-facilitating word recognition is that such motivations represent approach states, of heightened "approach to the environment." A reasonable view is that heightened hunger and thirst increase sensitivity to a wide range of incoming stimuli, which, from the standpoint of biological survival, permits improved search for food and water. Still to be answered is whether such heightened processing of incoming information occurs only for foveal input or also includes parafoveal input. The Ferguson studies used foveal viewing, but it is not known whether the facilitating effects of motivation are limited to such viewing. Motivation may facilitate only dominant input (Broadbent, 1971), or it may narrow the range of cue utilization (Easterbrook, 1959). Thus, under peripheral, parafoveal viewing, motivation may not facilitate word recognition. 
Stimuli projected parafoveally to the left or the right visual field (LVF or RVF) are initially processed by the contralateral hemisphere. Hemispheric asymmetry has been found for various states of emotion and for the perception of affectively positive or negative stimuli (Davidson, 1984; Dimond \& Farrington, 1977). It is not clear whether motivation also displays a lateralized bias similar to that reported for emotion. The present experiments address two questions: (1) Does hunger motivation facilitate word processing for parafoveally viewed words as was found for foveally viewed words? (2) If facilitation does occur, does hunger as an approach motivation reveal the RVF bias reported for positive effective stimuli and emotional states? That is, do hungry more than satiated subjects recognize RVF words sooner compared to words presented to the LVF?

\section{EXPERIMENTS 1 AND 2}

\section{Method}

Subjects. Forty undergraduate volunteers were tested, 10 men and 10 women each under foveal (Experiment 1) and parafoveal (Experiment 2) viewing conditions. Within each experiment, the subjects were randomly assigned either to refrain from eating for $12 \mathrm{~h}$ preceding testing or to eat a big meal within $1 \mathrm{~h}$ prior to testing. Right-handed subjects with $20 / 20$ or corrected-to-normal vision were tested at the students' usual lunch time. In Experiment 2, but not in Experiment 1, the subjects were tested twice: half were tested first hungry and then satiated, and the other half had the opposite test sequence. The first test in Experiment 2 used the list used in Experiment 1. The second test in Experiment 2, within 2 weeks of the first test, used a new list.

Apparatus. A Gerbrands three-field tachistoscope (Model G 1150A), a Gerbrands Lamp Drive Circuit unit, and a Gerbrands Digital Integrated Circuit unit (of the 300 series) were used. A Gerbrands Tachistoscope Logic 61159 unit controlled which of three fields was activated. A voice microphone and a clock counter measured vocal reaction times. A central-fixation $\mathrm{X}$ was visible before and after word exposure, with "catch" trials used for the parafoveal viewing condition. Luminosity was $3.83 \mathrm{~lm}$ in the three fields for Experiment 2 (parafoveal viewing) and $.52 \mathrm{~lm}$ for Experiment 1 (foveal viewing). The fields were lit throughout testing.

Procedure. In Erwin and Ferguson's (1979) and Ferguson's (1983) studies, one word was presented at a time until recognition. In the present experiments, however, two words were repeated in random alternation, on the left or the right side, until correctly recognized on two consecutive presentations. The parafoveal condition required this procedural change from the earlier studies to assure center fixation. When a word in one visual field was recognized to criterion, a new word appeared in that visual field regardless of what occurred in the other visual field. Number of presentations (trials) to recognition was counted independently for each word. With the stringent criterion of two consecutive correct recognitions, the subjects did not merely guess. The foveal condition also used two words, one per location. To assure foveal viewing, the subjects did not fixate on the central $\mathrm{X}$ prior to word onset, but were told instead to look left or right. The repeated words were exposed for $10 \mathrm{msec}$ for the parafoveal condition and $7 \mathrm{msec}$ for the foveal condition. In each experiment, on the average, a given word was not recognized on first presentation and was recognizable well within 40 presentations.

Words were selected on the basis of prior ratings for category exemplar status (see Ferguson, 1983, for a fuller description of word selection and testing procedure). Three categories were used. The list for Experiment 1 and for the first test of Experiment 2 had food words (rye, gum, cob, pie), animal words (fox, ram, elk, cow), and negatively emotional words (sin, hag, pus, woe). A second list was used in Experiment 2 . It provided a wider word sampling for the parafoveal viewing
Table 1

Mean Presentations to First Correct Word Recognition

\begin{tabular}{|c|c|c|c|c|c|c|}
\hline \multirow[b]{3}{*}{ Words } & \multirow{2}{*}{\multicolumn{2}{|c|}{ Foveal }} & \multicolumn{4}{|c|}{ Parafoveal } \\
\hline & & & \multicolumn{2}{|c|}{ List 1} & \multicolumn{2}{|c|}{ List 2} \\
\hline & Left & Right & Left & Right & Left & Right \\
\hline \multicolumn{7}{|c|}{ Hungry Condition } \\
\hline Food & 1.85 & 3.15 & 6.65 & 12.60 & 13.75 & 2.60 \\
\hline Animal & 2.75 & 2.10 & 6.60 & 7.00 & 8.45 & 9.50 \\
\hline Neg. Emot. & 2.45 & 4.70 & 13.05 & 11.80 & 8.40 & 11.95 \\
\hline \multicolumn{7}{|c|}{ Satiated Condition } \\
\hline Food & 2.40 & 14.45 & 6.35 & 15.00 & 9.60 & 4.85 \\
\hline Animal & 4.30 & 10.80 & 8.05 & 11.30 & 8.75 & 11.75 \\
\hline Neg. Emot. & 6.65 & 7.45 & 13.95 & 11.65 & 10.10 & 9.50 \\
\hline
\end{tabular}

Note-Neg. Emot. = negatively emotional words.

condition, for which no prior experimental data existed. The second list also had food words (nut, yam, fig, sip), animals words (ape ,pup, $r a t, e m u$ ), and negatively emotional words (foe, flu, pox, gun). Words were printed horizontally, in capital letters, with 35-point Varafont black lettering. For each testing, a given visual field contained six words, two per category. The visual angle of all words was between $2.25^{\circ}$ and $4.25^{\circ}$ from center fixation. First correct trial and criterion trial were highly correlated $(r>.94)$. To compare results with the earlier studies, number of trials to first correct recognition provided the main data.

\section{RESULTS AND DISCUSSION}

As seen in Table 1, under foveal viewing, even with the new procedure of word alternation (left and right), hunger significantly facilitated word recognition. A $2 \times 2 \times 3$ analysis of variance (ANOVA) for trials to first correct recognition in Experiment 1 showed motivation to be significant $[F(1,18)=5.88, M S e=114.06, p=$ $.026]$, the motivation $\times$ location interaction to be significant $[F(1,18)=4.92, M S e=42.14, p=.04]$, location to be significant $[F(1,18)=9.60, M S \mathrm{e}=42.14, p=$ $.006]$, and the motivation $\times$ category $\times$ location interaction to be significant $[F(2,36)=4.32, M S \mathrm{e}=21.11$, $p=.021]$. In contrast, motivation was not significant for either List 1 or List 2 under parafoveal viewing (Experiment 2). For both lists under parafoveal viewing, the only significant effect was the category $\times$ location interaction, with a reversed pattern for the two lists, as seen in Table 1 . For List 1 the interaction was $F(2,36)=6.78, M S \mathrm{e}$ $=30.82, p=.003$; for List 2 it was $F(2,36)=5.20$, $M S e=60.46, p=.01$. Under parafoveal viewing difficult words (e.g., gum) were comparably hard for the two motivation groups: however, under foveal viewing, only satiated, not hungry, subjects had poor performance with difficult words.

No need-relevant effects were found. This replicates the earlier Ferguson foveal data. Food words were not recognized significantly earlier by hungry than by satiated subjects. Without significant motivation effects for parafoveal viewing, no assessment was possible regarding an asymmetric bias for hunger. The visual field $x$ category interactions also gave no clear evidence regarding asymmetry for affective stimuli. 
Reaction times, analyzed by $2 \times 2 \times 3$ ANOVAs, showed that latency of first correct recognition was not affected by motivation, either for foveal or for parafoveal viewing. Under foveal viewing, hunger led to earlier recognition, but not to faster overt responding; hunger facilitated information processing but not response speed. A filter theory (Broadbent, 1971), which states that motivation facilitates processing dominant stimuli, is still tenable, if dominance is considered in terms of foveal viewing and not in terms of word difficulty. Further investigation is under way to clarify why motivation facilitates word recognition only under foveal viewing and not under parafoveal viewing.

\section{REFERENCES}

BOWER, G. H., \& CoHEN, P. R. (1982). Emotional influences in memory and thinking: Data and theory. In M. S. Clark \& S. T. Fiske (Eds.), Affect and cognition (pp. 291-331). Hillsdale, NJ: Erlbaum.

Broadbent, D. E. (1971). Decision and stress. New York: Academic Press.

DAVIDSON, R. J. (1984). Hemispheric asymmetry and emotion. In K. R. Scherer \& P. Ekman (Eds.), Approaches to emotion (pp. 39-57). Hillsdale, NJ: Erlbaum.

Dimond, S., \& FARRINGTon, L. (1977). Emotional response to films shown to the right or left hemisphere of the brain measured by heart rate. Acta Psychologica, 41, 255-260.

EASTERBROOK, J. A. (1959). The effect of emotion on cue utilization and the organization of behavior. Psychological Review, 66, 183-201.

ERwiN, R. J., \& FERGUSON, E. D. (1979). The effect of food and water deprivation and satiation on recognition. American Journal of Psychology, 92, 611-626.

FERGUSON, E. D. (1982). Motivation: An experimental approach. Melbourne, FL: Krieger.

Ferguson, E. D. (1983). The effect of motivation and word characteristics on recognition. American Journal of Psychology, 96, 253-266.
Fowler, C. A., Wolford, G., Slade, R., \& TASSinary, L. (1981). Lexical access with and without awareness. Journal of Experimental Psychology: General, 110, 341-362.

FUSTER, J. M. (1958). Effects of stimulation of brain stem on tachistoscopic perception. Science, 127, 150.

GraF, P., \& MANDler, G. (1984). Activation makes words more accessible, but not necessarily more retrievable. Journal of Verbal Learning \& Verbal Behavior, 23, 553-568.

Hellige, J. B., \& Cox, P. (1976). Effects of concurrent verbal memory on recognition stimuli from left and right visual fields. Journal of Experimental Psychology: Human Perception \& Performance, 2, 210-221.

Humphreys, M. S., \& Revelle, W. (1984). Personality, motivation, and performance: A theory of the relationship between individual differences and information processing. Psychological Review, 91, 153-184.

JaCOBY, L. L. (1983). Perceptual enhancement: Persistent effects of an experience. Journal of Experimental Psychology: Learning, Memory, \& Cognition, 9, 21-38.

Kunst-Wilson, W. R., \& Zajonc, R. B. (1980). Affective discrimination of stimuli that cannot be recognized. Science, 207, 557-558.

Malmo, R. B. (1957). Anxiety and behavioral arousal. Psychological Review, 64, 276-287.

MARCEL, A. J. (1983). Conscious and unconscious perception: An approach to the relations between phenomenal experience and perceptual processes. Cognitive Psychology, 15, 238-300.

McClelland, D. C., \& Liberman, A. M. (1949). The effect of need for achievement on recognition of need-related words. Journal of Personality, 18, 236-251.

SANFORD, R. N. (1937). The effect of abstinence from food upon imaginal processes: A further experiment. Journal of Psychology, 3, 145-159.

TAYLOR, J. A. (1956). Physiological need, set, and visual duration threshold. Journal of Abnormal \& Social Psychology, 52, 96-99.

Wispé, L. G., \& Drambarean, N. C. (1953). Physiological need, word frequency, and visual duration thresholds. Journal of Experimental Psychology, 46, 25-31.

(Manuscript received for publication October 5, 1987.) 